\title{
Priorities for Advancing Nursing Knowledge
}

Journal of Nursing Scholarship, 2002; 34:3, 211-212. @2002 Sigma Theta Tau International.

$\mathrm{T}$

he status of health and health care systems around the world indicates the great need for advancing nursing knowledge in research and practice. Because priorities might vary in different locations, the editor asked several nursing leaders around the world the following question:

"Advancing nursing knowledge to improve health of the world's people" is the mission of the Journal of Nursing Scholarship (JNS). I want to compile views of nursing leaders about areas of knowledge needed to improve the health of people throughout the world. I invite you as internationally recognized nursing leaders to send me your individual responses to this question:

"What do you think are the top three priorities for building nursing knowledge to improve health of people in your area?"

"Area" may be defined as geography, specialty, or interest. Statements should be as specific as possible to influence directions for nursing research and practice. Please avoid generalities, such as "improve nursing education," or "increase knowledge of research methods." A more specific example might be: "maternal education to reduce infant mortality." An enumeration of the priorities, with a brief description of the need, will be most helpful toward fulfilling this mission.

Below are the responses received by the time this issue went to press. JNS readers also are invited to send E-mail responses (tjns@u.washington.edu) for future issues.

The Editor

Such a provocative question, and I am glad you are asking it. With my work in the former Soviet countries and more recently with the United States Agency for International Development for Afghanistan and Pakistan, I see several common top priorities:

1. Health of women, infants, and children, especially with an initial focus on infant and maternal mortality. These and many other countries have experienced major political and economic upheavals, and the care of women in general falls way behind, particularly in some of the Islamic countries.

2. Assessment and management of infectious diseases, with emphasis on rural areas (particularly to malaria, tuberculosis, and HIV/AIDS).

3. Nutrition and public health - this topic might sound like a tie for third place, but nutrition and public health are significantly related to each other. Community nursing and primary care models for addressing these needs are very rare.

Another priority is to determine what to teach students about being open to and cognizant of pressing international and global health issues. Electives and majors are needed at graduate level.

\footnotetext{
Sheila Ryan, RN, PhD, FAAN Omaha, Nebraska, USA saryan@unmc.edu
}

I would like to respond to your question on the top three priorities for building nursing knowledge to improve the health of people in my country:

1. Improve the status and health of women: reduce maternal mortality and morbidity, improve reproductive health and women's nutrition, lessen the gender gap, and promote empowerment of women. Care of women should receive top priority.

2. Improve infant and child health: reduce infant mortality (especially neonatal) and the morbidity and mortality of children. Issues such as growth and development and nutrition are important topics in promoting child health.

3. Control infectious diseases.

$$
\begin{array}{r}
\text { Maaly Guimei, RN, PhD } \\
\text { Alexandria, Egypt } \\
\text { mguimei@internetegypt.com }
\end{array}
$$

I propose these three needs as top priorities for nursing knowledge to improve health of people throughout the world:

1. Obtain good data on the relevant health issue.

2. Develop skills of people to properly analyze the data.

3. Develop skills of people to use the results of the analysis, create a message, and communicate the 
message to all the relevant parties such as the media, public sector, private sector, and others.

\section{Peter Buerhaus, RN, PhD, FAAN \\ Nashville, Tennessee, USA peter.buerhaus@vanderbilt.edu}

The following is my list of priorities for building nursing knowledge to improve human health:

1. Educate our students about the dire needs in other parts of the world for health care, especially regarding infectious diseases and the poverty and oppression under which many people live. Particular emphasis is needed on health of children and women.

2. Guide our students to study problems of worldwide significance, not just significance for the US.

3. Test research hypotheses in more than one country; this approach will enhance the external validity of findings.

\section{Shake Ketefian, RN, EdD, FAAN Ann Arbor, Michigan, USA Ketefian@umich.edu}

An overall general priority for producing direct effects on health is research focused on developing biobehavioral nursing interventions and clinical therapeutics that are culturally sensitive to the health needs of people individually as well as at the community level, and evaluating the effects on health outcomes. An urgent need is to generate knowledge to enable individual nurses to accomplish desired outcomes. The following are priorities for producing indirect effects on the health of people, but are critical for nurses to study.

First, design and test a professional nursing practice model that will yield high-quality and cost-effective health care services that satisfy both consumers and professional nurses. This issue has been raised and discussed in various forums over the past decades, but it still requires critical appraisal and development efforts. Perhaps what needs to be done is to test more vigorously what is known and make a case for nationwide or international attention. Major factors to consider for the developing of this model are: delineation of the roles, compensation, and career development of professional nurses, technical nurses, and technical assistants; uniform educational standards and credentials for nursing care services (e.g., BSN as the minimum level for professional nursing, master's prepared APNs leading the practice model, and doctorally prepared nurses working in clinical settings for education and research). This model should include appropriate staffing mix and staff-to-patient ratios for various clinical settings. Such a model should ultimately be a drawing card for recruiting young generation of nurses who seek careers that allow them to utilize scientific knowledge and technological skills for human services, to exercise judgment for ethical and quality care, to grow professionally and move upward in a career trajectory, and to enjoy life with flexible schedules and appropriate compensation.
Second, find ways to increase the efficiency of health care delivery. Nurses should study factors that influence and improve the efficiency of nursing service delivery, affect costs of nursing services, and generate revenues, rather than having nursing considered only a cost. Development of leadership and management skills at all levels of nursing is thought to improve overall productivity and efficiency, and this hypothesis should be tested.

The third priority is to examine the benefits, risks, barriers, and difficulties in increasing collaborative, interdisciplinary, international research projects. Extending knowledge beyond disciplinary and national boundaries is a good thing to do, but nurses must critically examine this activity to benefit all who are involved.

Mi Ja Kim, RN, PhD, FAAN Chicago, Illinois, USA, and Seoul, Korea 